\title{
Planning for quality in the NHS breast screening programme
}

\author{
J A Muir Gray
}

\section{Managing innovation}

The development of health services world wide has been piecemeal and uncoordinated. Some control has been exerted over health service resources by controlling capital and by manpower strategies, but these are relatively crude methods largely concerned with control of resources and not with quality of health care provided. The main determinant of the quality of health care is the behaviour of individual professionals, and the innovation of professional practice has been neither systematic nor planned. Consequently professional practice consists only in part of tried and tested interventions; most health professionals also continue to use interventions whose effectiveness is limited and are slow to adopt new interventions of proved effectiveness. ${ }^{12}$ The main reason for this has been managerial hesitation to interfere with "professional freedom," but even the health professions now realise that more systematic approaches to innovation must be taken, either through managerial research and development strategies or through professionally led innovation. The importance for quality assurance is that for the first time the first stage in the three phases of quality assurance identified by Juran $^{3}$ - namely, quality planning - can be undertaken. Most quality improvement and audit initiatives are attempting to create a more systematic approach to clinical practice in a world in which the main impression is of brownian motion rather than systematic and scientific progress towards better quality.

Planning for quality before an intervention is introduced is particularly important in screening because the ethical contract between a health service providing screening and a healthy population is different from that between an individual clinician offering help to someone actively seeking it because they perceive they have a problem. This article describes the use of quality planning in setting up a new health service.

\section{Setting up a national breast screening programme}

In 1988 a working group set up by the Department of Health and chaired by Professor Sir Patrick Forrest presented a report to the four health ministers of the United Kingdom departments of health. Its remit was to review the evidence of the effectiveness of breast screening and to make recommendations concerning feasibility and implementation of screening. The group's recommendation that breast cancer screening be introduced in the United Kingdom was accepted. ${ }^{4}$

There had, however, been considerable concern in the United Kingdom about the lack of effectiveness of cervical screening, ${ }^{5}$ and because of this steps were taken to ensure that breast cancer screening would not experience the problems associated with cervical screening after its gradual, piecemeal, and uncontrolled introduction during the 1960s. A decision was taken to introduce breast cancer screening in a systematic fashion, managing the introduction nationally, while ensuring local accountability and leadership of the programme.

\section{Principles}

The NHS breast screening programme was introduced on three main principles:

- The need for high quality

- The importance of people

- The systems approach.

NEED FOR HIGH QUALITY

The Forrest report emphasised the need to provide a high quality service, both because high quality screening is necessary to ensure that benefits outweigh adverse effects and because screening is offered to healthy populations who have not sought help but are sought out and invited to participate.

There was general agreement, therefore, that the screening programme should be quality driven - namely, that the management of the service should focus on quality standards rather than simply on measures of cost or work rate.

It was decided to base the whole screening programme on the principles of total quality management - namely, the maintenance of minimum standards and the continual search for quality improvement - and the approach used in developing the screening programme as a total quality system is elegantly described in a triangle first popularised by Joiner Consultancy, an American firm of industrial consultants (fig 1).

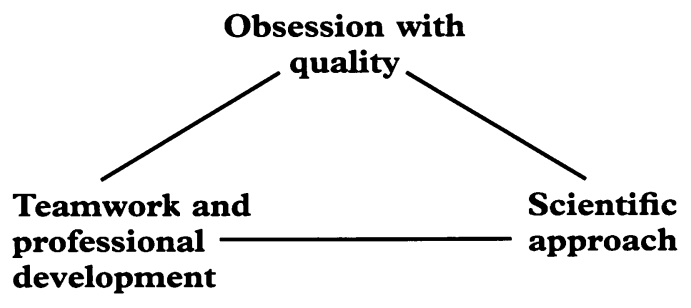

Fig 1 foiner triangle 
IMPORTANCE OF PEOPIE

In planning or running a screening service much attention is focused on the problems of buying and maintaining mammography equipment or on the computerisation of the information system, but the screening is delivered by people and run by people and, as the Joiner triangle indicates, equal emphasis must be given to the development of individuals and teams as to that of the more scientific aspects of a screening programme.

In considering the development of the professional skills involved, the programme was based on the principle that there were enough people with adequate skills to achieve the necessary degree of quality but that it would have to give much more attention to the development of professionals than was customary in the NHS. This meant that the programme had to take into account, at every stage and every level, the three main determinants of professional practice: competence, motivation, and values. The quality of professional performance is a function of these three variables, being directly related to competence and motivation and inversely related to the barriers that individuals have to overcome. This relation is elegantly described by the format developed at McMaster University:

$$
\mathrm{P}=\mathrm{CM} / \mathrm{B},
$$

where $\mathrm{C}=$ competence, $\mathrm{m}=$ motivation, $\mathrm{b}=$ barriers.

NEED FOR A SYSTEMS APPROACH

Breast screening is too often considered as being synonymous with mammography, but in the NHS breast screening programme screening was considered to consist of all those steps that could identify cancer in previously healthy women, ranging from the identification of eligible women to the histological analysis of biopsy specimens. These activities, however, had to be linked within a single system, the definition of a system being a set of activities focusing on a single set of objectives. The implication of this was for much clearer management and leadership of the programme than is presently conventional in clinical work in the United Kingdom.

\section{Quality planning in setting up the system}

The four basic elements which integrate several activities into a system are a set of common objectives, criteria by which progress towards those objectives can be measured, standards which indicate how much progress is being made, and the information system which allows feedback to help programme managers and individual professionals.

SETTING OBJECTIVES

The aim of the screening programme is to minimise mortality from breast cancer in women eligible for screening. Table 1 sets out specific objectives.
CHOOSING VALID CRITERIA

After the objectives have been chosen the next step is to identify valid and reliable criteria that can be used to measure performance. Criteria are currently being clarified and amplified, and a draft set of criteria for evaluation and quality assurance have been published." The most difficult criteria to identify are those which measure the reactions of the women served by the programme.

SETTING STANDARISS

One definition of quality assurance is that it is concerned with the continual pursuit of excellence; although it is useful to "pursue excellence," its relevance is limited because excellence is often the result of a chance collection of individuals and circumstances which cannot easily be reproduced. For this reason the breast screening programme focused on two other types of standard: the minimum acceptable standard and the achievable standard.

The definition of a minimum acceptable standard is self evident, and the standards in table 1 illustrate the approach used in setting minimum standards. The working group of the Royal College of Pathologists, which produced a report on quality assurance, "also issued more detailed standards against which professionals can measure their performance, as have the Royal College of Radiologists ${ }^{\top}$ and the College of Radiographers.

However, most programmes will probably meet minimum acceptable standards, and it is therefore necessary to identify a second type of standard against which they can measure their performance - namely, the achievable standard. When sufficient data have been gathered from a sufficient number of programmes this standard will probably be set simply by defining the cut off point between the top quartile and the remainder of the programmes.

\section{Managing for quality}

The NHS breast screening programme is managed at three different levels: the population based screening programmes, the regional quality assurance programmes, and the national programme.

POPLLATION BASED SCREENINC PROCIRAMIMES The health service in England is currently divided into 190 health authorities. The Forrest report recommended that screening should be provided for larger populations than the population of the average health authority to achieve economies of scale and to ensure sufficient throughput for good quality work to be achieved nation wide. Although it was not possible to cover populations as large as those recommended in the report, the whole of England is covered by 77 screening programmes, each of which has a defined programme manager and has the responsibility of providing a service for a defined population. In delivering the programme close links with primary care are essential, making use of the fact that almost all 
Table 1 Objectives, criteria, and standards of the NHS breast screening programme

\begin{tabular}{|c|c|c|}
\hline Objective & Criteria & Acceptable standard \\
\hline \multirow[t]{4}{*}{ (1) To achieve optimum quality } & High contrast spatial resolution & $\begin{array}{l}8.9(20 \text { Bar groups) line pairs per } \\
\mathrm{mm}\end{array}$ \\
\hline & Low contrast spatial resolution & $\begin{array}{l}3 \cdot 2 \text { (6 Bar groups line) pairs per } \\
\mathrm{mm}\end{array}$ \\
\hline & $\begin{array}{l}\text { Large area, low contrast contrast } \\
\text { detectability } \\
(6 \mathrm{~mm} \text { detail })\end{array}$ & 7 Details \\
\hline & $\begin{array}{l}\text { Small detail contrast detectability } \\
(0 \cdot 5,0 \cdot 25 \text { detail })\end{array}$ & 7 Details \\
\hline (2) To limit radiation & $\begin{array}{l}\text { Average glandular dose to breast } \\
\text { using a grid }{ }^{\star}\end{array}$ & $<5 \mathrm{mGy} /$ view \\
\hline $\begin{array}{l}\text { (3) To minimise number of retake } \\
\text { films }\end{array}$ & Number of retake films $\dagger$ & $<3 \%$ of total films used \\
\hline $\begin{array}{l}\text { (4) To minimise number of } \\
\text { women referred unnecessarily } \\
\text { for further tests }\end{array}$ & Onward referral to assessment & $<10 \%$ of women screened \\
\hline $\begin{array}{l}\text { (5) To minimise number of } \\
\text { missed cancers in women } \\
\text { screened }\end{array}$ & $\begin{array}{l}\text { In the prevalent round the } \\
\text { proportion of cancers presenting } \\
\text { in screened women in subsequent } \\
12 \text { months }\end{array}$ & $<6$ in 10000 \\
\hline $\begin{array}{l}\text { (6) To maximise number of } \\
\text { cancerss detected }\end{array}$ & $\begin{array}{l}\text { In the prevalent round the } \\
\text { proportion of cancers detected in } \\
\text { women invited and screened }\end{array}$ & $>50$ in 10000 \\
\hline $\begin{array}{l}\text { (7) To maximise number of small } \\
\text { cancers }\end{array}$ & $\begin{array}{l}\text { In the prevalent round the } \\
\text { proportion of cancers less than } 10 \\
\text { mm in diameter (pathological } \\
\text { measurement) detected in women } \\
\text { invited and screened }\end{array}$ & $>15$ in 10000 \\
\hline $\begin{array}{l}\text { (8) To minimise number of } \\
\text { unnecessary invasive } \\
\text { procedures }\end{array}$ & Benign to malignant biopsy ratio & $<3$ \\
\hline
\end{tabular}

*Average glandular dose for a $45 \mathrm{~mm}$ thick standard breast.

tThe term "retake" is used to accommodate both reject and repeat films. A reject film is one which has been deemed useless and thrown away. A repeat film is one which has been repeated purely to provide improved information - for example improving patient positioning.

women are registered with a general practitioner and react positively to invitations from, or supported by, him or her.

REGIONAL QUALITY ASSURANCE PROGRAMMES Six different quality assurance domains were identified, covering the six main aspects of the programme.

- The acceptability of the programme to women ${ }^{8}$

- Mammography

- Pathology

- Treatment and follow up

- Information systems

- Programme management.

Each of the 14 regions in England was given responsibility for developing a quality assurance programme for the population based screening programmes within its region and was asked to identify one person to act as the quality assurance manager and to set up a quality assurance reference centre with special funds earmarked for this purpose. ${ }^{9}$

NATIONAL INITIATIVES

When setting up the programme six national initiatives were funded and managed by a small team.

- Coordination of research

- Policy review and evaluation

- Education and training

- Equipment appraisal

- Information systems

- Quality assurance.
Coordination of research - The United Kingdom Coordinating Committee on Cancer Research was asked to coordinate research on breast cancer screening and set up a special subcommittee to do so. This committee pulls together the main cancer charities and the four health departments.

Policy evaluation - The Department of Health set up an advisory committee chaired by Professor Martin Vessey, professor of community medicine at the University of Oxford to oversee the introduction of the programme and evaluate its effectiveness. ${ }^{10}$

Education and training - Four training centres were established in England to provide training for radiographers and radiologists, but these were integrated into a training initiative which included the education and training of primary care teams, pathologists, surgeons, nurses, information systems staff, physicists, and programme managers, as well as ensuring that women themselves were appropriately informed and educated. ${ }^{11}$

Equipment appraisal - Special funds were earmarked for appraising equipment and providing advice, which was undertaken by a branch of the Department of Health.

Information systems - Resources were invested to develop an information system which would not only identify and invite eligible women and follow up those with positive mammograms, but which would also provide information for programme managers and individual professionals to facilitate 
programme management and quality assurance.

Quality assurance was initially identified as a separate national initiative, but all of the preceding initiatives can be considered as making a contribution to quality assurance, and as the programme moved into its second phase, after the three year phase in which it was set up, several of these initiatives became subsumed in the quality assurance initiative.

MANAGEMENT OF THE SYSTEM NATIONALLY The 14 regions have played a pivotal part in the development of the programme; in each an individual was to develop the population based screening programmes and the regional quality assurance programmes, and a strong feature of the management has been the way in which these individuals have worked as a team. In addition, almost all the professional initiatives have had a "Big 18 " input with one representative of each profession from each of the 14 English regions and one from Scotland, Wales, and Northern Ireland and the private sector working together to develop, for example, quality assurance guidelines, pathology, or radiology.

Table 2 shows the early results of the programme, which are encouraging.

Evidence and experience since Forrest The Department of Health's advisory commitee produced a report in 1991 drawing together the research evidence available to it but not to the regional working group and reviewing its first three years' experience since the introduction of the national breast screening programme. ${ }^{12}$ The report concluded that all the research evidence was consistent in showing that breast cancer screening reduced cancer mortality in women offered it. It estimated the reduction in mortality to be about $40 \%$ in women screened and about $25 \%$ in the whole population offered screening, with a $70 \%$ acceptance of screening. It considered that the adverse effects of screening had not been underestimated by the Forrest report and that the early results from the programme indicated that adequate levels of

Table 2 Early results of NHS breast screening programme

\begin{tabular}{llc}
\hline \multicolumn{1}{c}{ Objective } & \multicolumn{1}{c}{$\begin{array}{c}\text { Minimum } \\
\text { standard }\end{array}$} & $\begin{array}{c}\text { Performance } \\
\text { achieved after } \\
957326 \\
\text { women } \\
\text { screened }\end{array}$ \\
\hline $\begin{array}{l}\text { To cover the } \\
\text { population at risk }\end{array}$ & $\begin{array}{l}\text { More than } 70 \% \\
\text { of women invited } \\
\text { never attended }\end{array}$ & $71 \cdot 4 \%$ \\
$\begin{array}{l}\text { To minimise } \\
\text { adverse effects by } \\
\text { minimising the } \\
\text { proportion of } \\
\text { women recalled }\end{array}$ & $\begin{array}{l}\text { Not more than } \\
10 \% \text { of women } \\
\text { who have a } \\
\text { mammogram } \\
\text { should be } \\
\text { recalled }\end{array}$ & $7 \cdot 1 \%$ \\
$\begin{array}{l}\text { To minimise } \\
\text { number of } \\
\text { biopsies }\end{array}$ & $\begin{array}{l}\text { Less than } 1 \cdot 5 \% \\
\text { of women should } \\
\text { have a biopsy }\end{array}$ & \\
To detect cancer & $\begin{array}{l}\text { More than } 6 \cdot 0 \\
\text { cancers should be } \\
\text { detected per } \\
1000 \text { women } \\
\text { screened }\end{array}$ & \\
\hline
\end{tabular}

quality were being achieved to produce a reduction in mortality, although this reduction would not become evident until the year 2000 .

\section{Implementing innovations}

Juran emphasised the need to undertake quality planning before introducing a new product or process. ${ }^{3}$ Figure 2 shows how quality planning relates to quality control and quality improvement. Most audit and quality improvement in the health service focuses on services or interventions which were introduced without quality planning. The pattern of health service development in the past has been one of piecemeal development, but can we allow this process to continue, either in screening or in clinical care?

IMPLEMENTING SCREENING INNOVATIONS

New screening tests should always be implemented with the approach described in this article - namely, with clear national leadership, based on the principles of total quality management, and with authority vested in that leadership to ensure national standards and systems of quality assurance.

The contract between the persons screened and the screener is different from that between clinician and patient, for in screening we are intervening in the life of someone who was previously healthy. Furthermore, screening often operates on a very fine balance between benefit and harm, and high quality screening is essential to ensure that the benefits outweigh the adverse effects. In addition, screening almost always involves very many people, and therefore small drifts in quality can have major effects - for example, a $1 \%$ change in the referral rate for colposcopy means that another 40000 women a year are referred.

At present new screening services can be introduced in a piecemeal fashion, and two services currently drifting into practice in the United Kingdom - screening for Down's syndrome and cholesterol screening - should be run as national public health screening services, with clear accountability locally for the quality of the service delivered to local populations but a clear national policy and programme of quality assurance.

IMPLEMENTING CLINICAL INNOVATIONS

There is an ethical basis for managing the implementation of a new screening service,

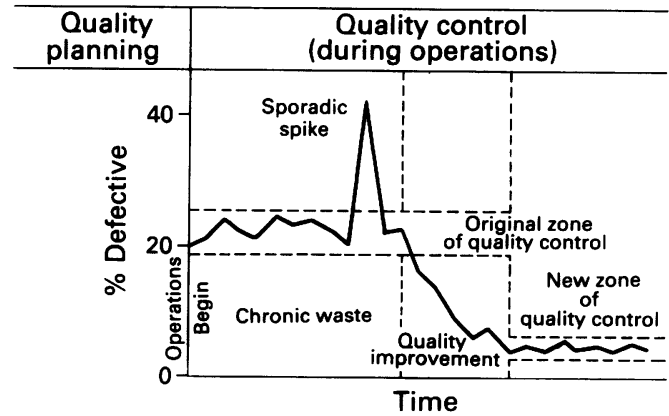

Fig 2 furan trilogy 
but the introduction of a new clinical service also needs management and quality planning.

Some drugs are relatively cheap and harmless and when introduced to the market can be adopted by the medical profession without inappropriate or inefficient use of resources. Other drugs, however, are expensive, have side effects, and are appropriate for only a small subset of patients with a particular condition or disease. The same could be argued for new surgical operations or diagnostic tests, in which the case for managing innovation and quality planning is even stronger because new diagnostic tests and surgical treatments do not have to run the gauntlet of clinical trials and licensing checks.

In the past, innovation in health care has not been managed; in the future it must be. This has been recognised in the United Kingdom by the introduction of a Research and Development Strategy, and the health professions would be wise to adopt the proposal that innovation should be more rigorously managed with enthusiasm. If they do, then they will play a full part in the management of innovation and quality planning. If they do not, others will.

1 Enkin M, Keirse MJNC, Chalmers I. A guide to effective care in pregnancy and childbirth. Oxford: Oxford Medical Publications, 1990.

2 Wyatt J. Use and sources of medical knowledge. Lancet 1991;338:1368-73.

3 Juran JM, Gryna FM. furan's quality control handbook. New York: McGraw-Hill, 1988.

4 Department of Health and Social Security. Breast cancer screening. Report of Department of Health Working Group. London: HMSO, 1988.

5 Department of Health and Social Security. Guidelines on the establishment of a quality assurance system for the radiological aspects of mammography used in breast screening. London: aspects of mam

6 Royal College of Pathologists. Guidelines for pathologists. London: RCPATH, 1990.

7 Royal College of Radiologists. Quality assurance guidelines for radiologists. Oxford: NHSBSP Publications, 1990.

8 Gray JAM, Austoker J. Draft guidelines on improving acceptability. Oxford: NHSBSP Publications, 1989.

9 Department of Health. Quality assurance for mammography. London: DOH, 1989. (HC(89)6.)

10 Department of Health Advisory Committee. Breast cancer screening 1991: evidence and experience since the Forrest screening 1991: evidence and
report. London: DOH, 1991.

11 Cook J, Knight D, Taylor V, Austoker J, Gray JAM. Health education draft guidelines. Oxford: NHSBSP Publications, 1989.

12 Gray JAM. Breast cancer screening 1991: evidence and experience since the Forrest report. Oxford: NHSBSP Publications, 1991. 